\title{
RE-DESIGN PRUSA I3 3D PRINTER USING SOFTWARE SOLIDWORKS 2016
}

\author{
IMAM MARDIYANSAH \\ Post Graduate Program, Department of Manufacturing Management \& Engineering, \\ Gunadarma University, J1 Margonda No.100 Depok, Indonesia.
}

\section{MOHAMAD YAMIN}

The Chairman of the Department of Post Graduate Program Manufacturing Management \& Engineering, Gunadarma University, Jl Margonda No.100 Depok, Indonesia.

\begin{abstract}
Rapid Prototyping is a technology related to physical objects which are directly derived from the CAD data. This method can produce objects by stacking material in layers. This technology is often called addictive manufacture, there are five of the most common rapid prototyping uses, namely: visualization, appropriate forms, product testing, tools, and use of spare parts. One example of a machine that uses rapid prototyping is a $3 D$ printer. In this study discussed about designing and creating a $3 d$ printer using the FDM method, Where FDM utilizes material extruded from a nozzle which is then driven by a motor. The material is a thread-shaped thermoplastic (coil) which is heated above the melting point by the heater and then extruded through the extruder nozzle hole. The heater maintains that temperature and deforms the material from the solid to semi-solid (liquid) so that it is easy to extrude. The moving nozzle and removing the extrusion liquid form a layer. convection heat transfer at the nozzle, then get the results of the analysis of $208^{\circ} \mathrm{C}$ and use the nozzle type E2A57. After that, analysis of filament thrust to find the amount of force required for the driving roller so that the filament can flow (due to impulse) to the heater and to determine the filament shift speed (due to the driving force of the roller) and motor rotation speed needed to produce the melt speed that comes out from the nozzle according to $25 \mathrm{~mm} / \mathrm{s}$.
\end{abstract}

Keywords: Rapid Prototyping, FDM, E2A57, Filament.

Cite this Article: Imam Mardiyansah and Mohamad Yamin, Re-Design Prusa I3 3D Printer Using Software Solidworks 2016, International Journal of Design and Manufacturing Technology (IJDMT) Volume 10, Issue 1 (2019) pp; 1-11 http://www.iaeme.com/ijdmt/issues.asp?JType=IJDMT\&VType=10\&IType $=1$ 


\section{INTRODUCTION}

Rapid Prototyping is a technology related to physical objects that are obtained from the CAD. This method can produce objects by way of stacking the ingredients layers in layers. This technology is often also referred to as addictive manufacturing, there are five of the most common use of rapid prototyping: visualization, the appropriate forms, test products, tools, and the use of spare parts. One example of a machine that uses rapid prototyping is a $3 \mathrm{D}$ printer. 3D-Printing is a new breakthrough in the world of technology. 3D-Printing is a printer able to print 3-dimensional objects. Advantages of 3D-Printing is very possible to make different shapes of patterns. This is due to the motion of the printer in 3 coordinates. Associated with the definition 3D-Printing can function in the world of manufacturing. 3d printer is a method of making prototyping in a short time on the process of product development, rapid prototyping technology needed in competition the manufacturing industry especially in the era of products with a short life cycle such as currently. The existence of these problems then authors takes the theme of the thesis is to design, redesign and analyze the rapid prototyping: $3 \mathrm{~d}$ printers type Fused with Deposition Modelling (FDM) using the type of raw material Polylactic Acid (PLA) filament diameter $1.75 \mathrm{~mm}$. Therefore, the authors compiled a thesis with the title "Designing a 3D Printer Rapid Prototyping Using Software Solidworks 2016".

\section{LITERATURE}

Rapid prototyping $(R P)$ can be defined as the methods used to create the model scale (prototype) of the starting part of a product (part) or assembled product (assembly) quickly by using data of computer aided design (CAD) three dimensions. Rapid prototyping allows the visualization of a three-dimensional images become three-dimensional objects that have a volume of original. Fused Deposition Modelling (FDM) is a Rapid Prototyping method that utilize material extruded from a nozzle that is then driven by the motor. The material is a thermoplastic shaped yarn (coil) that is heated above the melting point by the heater is then extruded through the vent extruder nozzle. Maintain the temperature of the heater and deformation material from a solid into a semi-solid (liquid) for easy extruded. Moving nozzle and dispense liquid extrusion forming layer. Plastic extrusion material will harden quickly once issued passes through the nozzle. After the first layer is formed, the platform moves down and then is the process of the formation of the next layer.

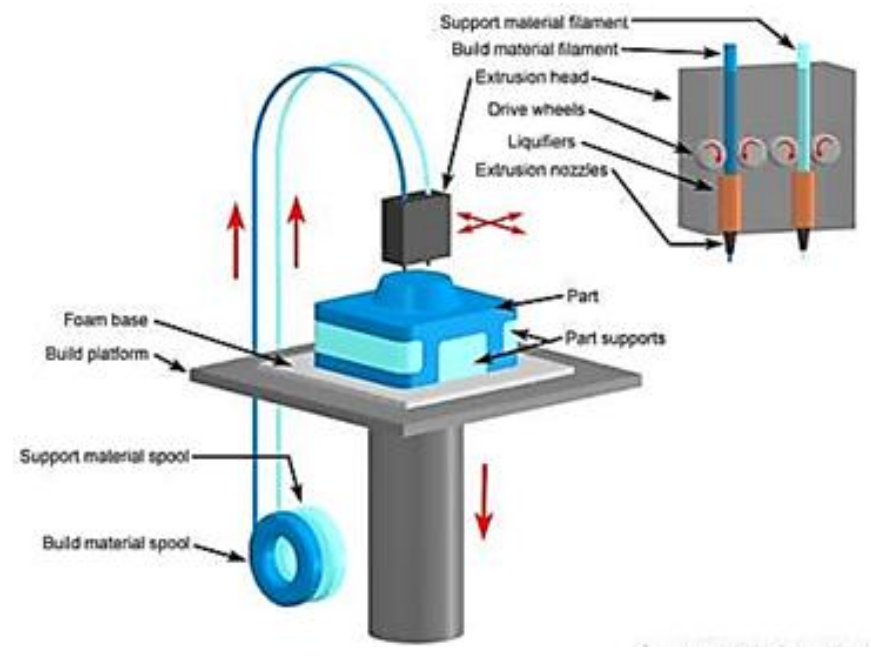

Figure 1 Fused deposition modelling. 


\section{RESEARCH METHODS}

In the exercise of an activity of research, usually always starts with the determination of stages or steps of research. The following will be explained about the method of research conducted from beginning to end, research is shown through a flowchart.

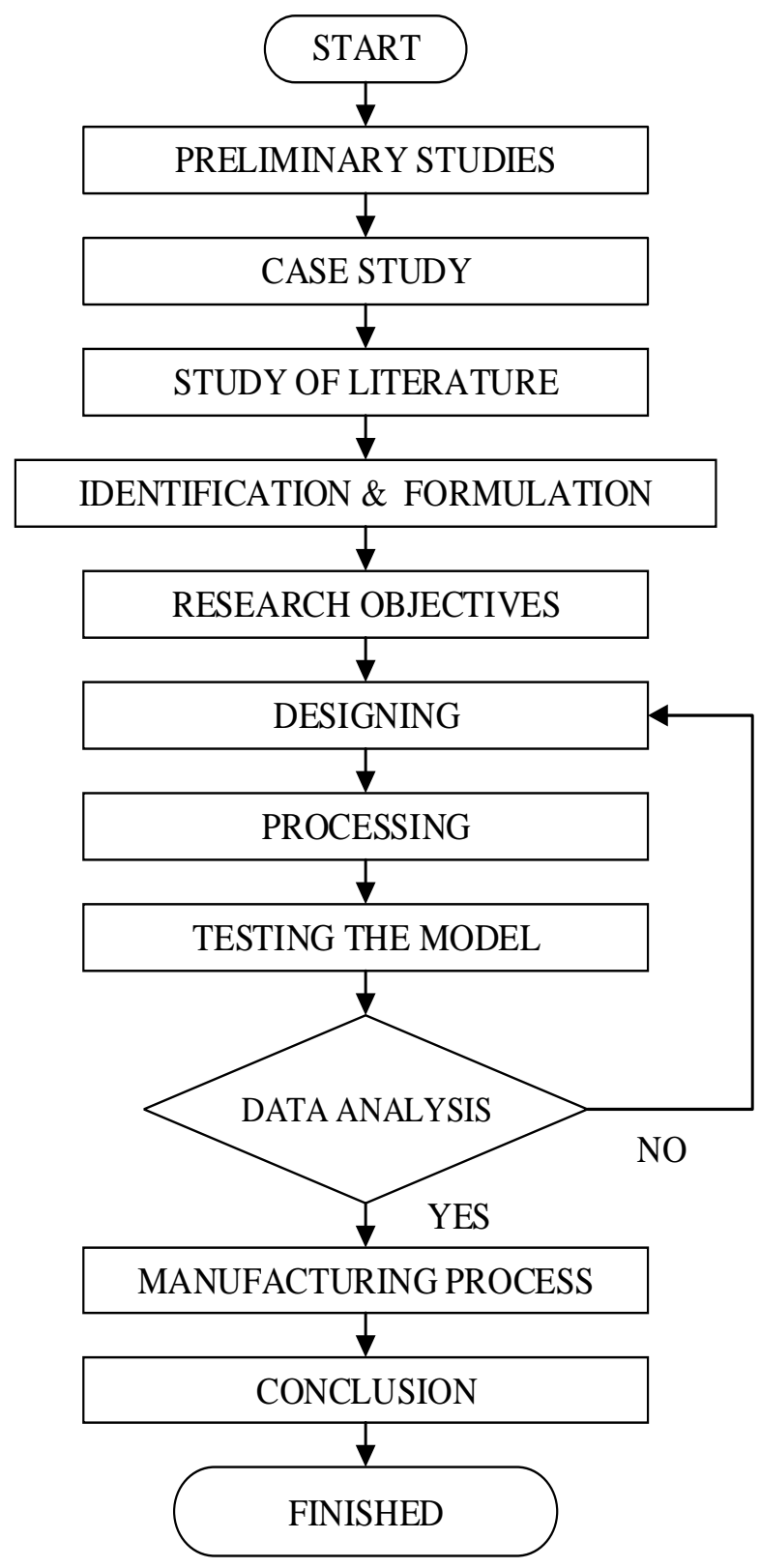

Figure 2 Research flowchart.

Early stage does is study the literature thoroughly to get the initial data on the 3D printer will be created based on FDM method. Then determine the required design parameters such as length. width, height, weight, electric components and others.

\subsection{Design of a 3D Printer}

In designing a product in advance of knowing and making the necessary data. So, the machining process can take place properly. The design of the model is used to create a model with a Hot Bed $214 \times 214 \times 3 \mathrm{~mm}$ and using a filament size diameter $1.75 \mathrm{~mm}$ by the type of PLA. 

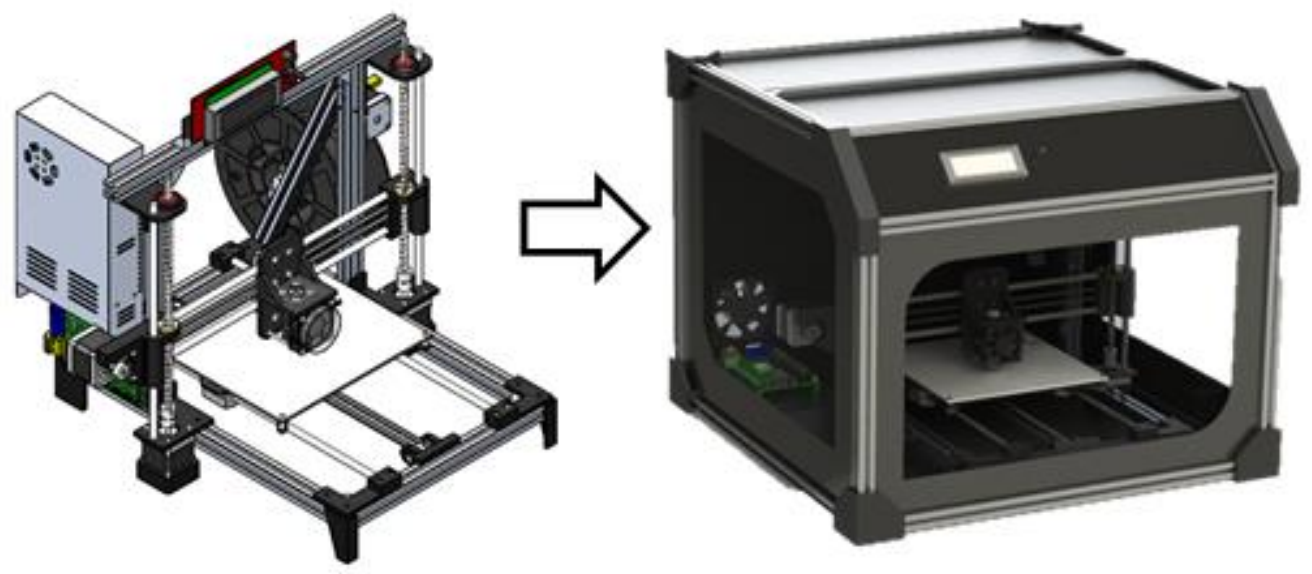

Figure 3. Design printer 3D.

\subsection{The selection of Model/Topology 3d Printer}

Models used in 3d printer is using a model of Fused Deposition Modelling (FDM). Utilizing the material extruded from a nozzle that is then driven by the motor. The material is a thermoplastic shaped yarn (coil) that is heated above the melting point by the heater is then extruded through the vent extruder nozzle. Maintain the temperature of the heater and deformation material from a solid into a semi-solid (liquid) for easy extruded. Moving nozzle and dispense liquid extrusion forming layer.

\subsection{Assembly of Electrical Components}

The process of assembling electrical components between the mechanical components. Placement-placement of sensors to note to match the course of the program. Electric components Assembly can be seen in fig 4.

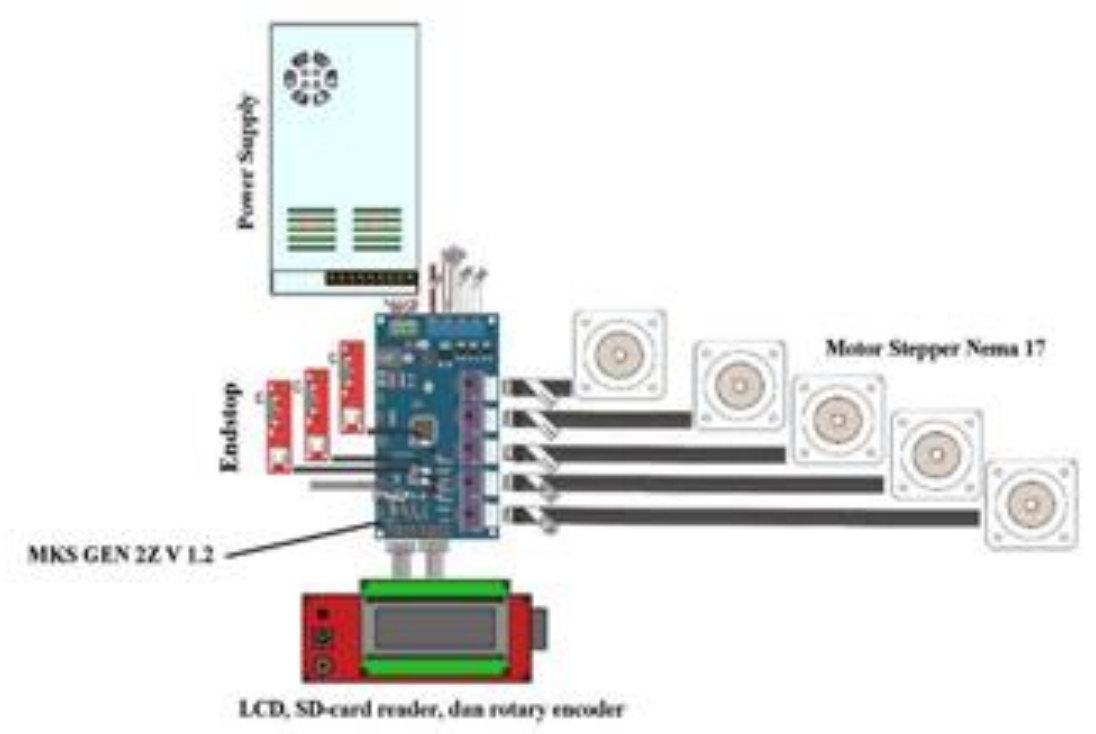

Figure 4 Assembly of electrical components 
Table $13 D$ Printer specifications.

\begin{tabular}{|c|c|c|}
\hline No & Specifications & Description \\
\hline 1 & Printer 3D Model & Fused Deposition Modelling (FDM) \\
\hline & \multirow{3}{*}{ Nozzle } & Diameter Filament $1.75 \mathrm{~mm}$ \\
\cline { 1 - 1 } \cline { 3 - 3 } & & The diameter of the discharge at the tip of the nozzle $0.4 \mathrm{~mm}$ \\
\cline { 3 - 3 } & & The speed of discharge Filament in nozzle $25 \mathrm{~mm} / \mathrm{s}$ \\
\hline \multirow{2}{*}{3} & Material melting point & PLA \\
& of filament & $190-210^{\circ} \mathrm{C}$ \\
\hline \multirow{3}{*}{4} & PCB Heat Bed & MK $2 \mathrm{~b}$ \\
& PCB dimensions & $214 \mathrm{~mm} \times 214 \mathrm{~mm}$ \\
& Work area & $200 \mathrm{~mm} \times 200 \mathrm{~mm}$ \\
\hline
\end{tabular}

\section{RESULTS AND DISCUSSIONS}

In making the design of $3 \mathrm{~d}$ printers using FDM model utilizing the material extruded from a nozzle that is then driven by the motor. The material is a thermoplastic shaped yarn (coil) that is heated above the melting point by the heater is then extruded through the vent extruder nozzle. Maintain the temperature of the heater and deformation material from a solid into a semi-solid (liquid) for easy extruded.

\subsection{Analysis of Heat Transfer}

Heat transfer that occurred on 3D printer namely the extruder which took place at the heater, where the heat energy generated by the cartridge heater (heating element) propagate through the heater filament towards a certain temperature, heat energy that propagates in the filament is used to convert the form of filament from solid to plastic melt. Temperature on the other components of the electric components.

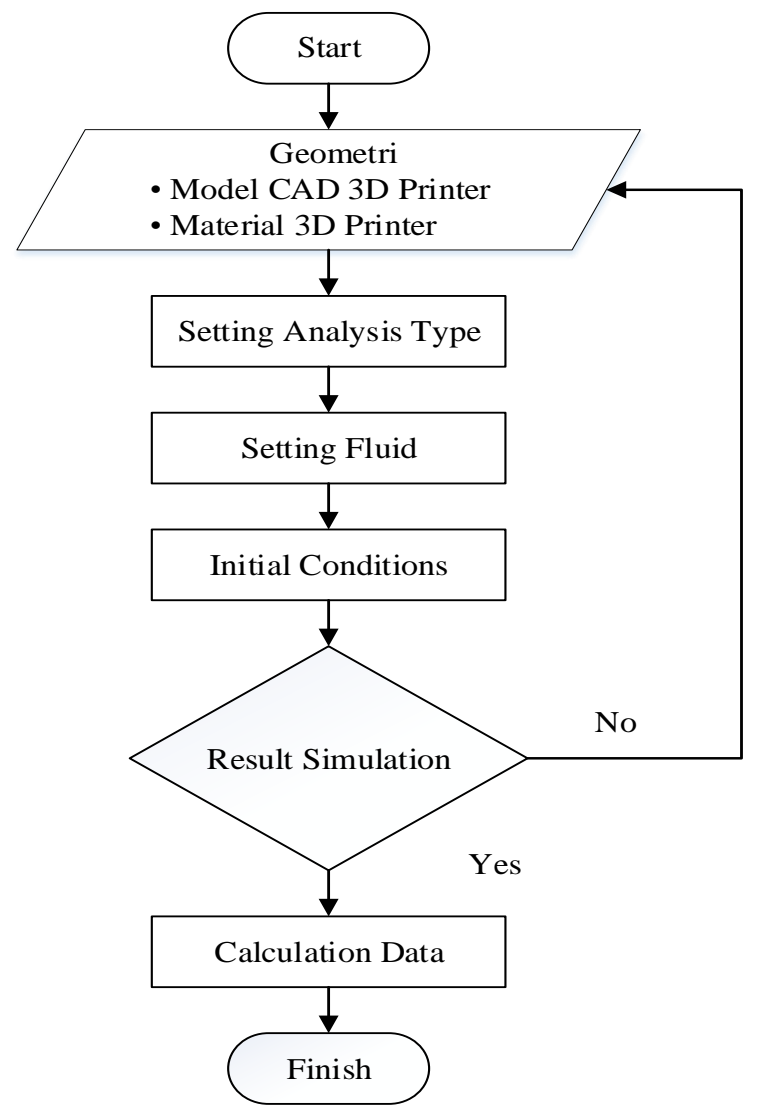

Figure 5 Flow Chart Flow Simulation Thermal 3D Printing. 
To analyze heat transfer that occurs in the heater has been designed, the author uses the CAE as a tool of analysis. the software used is the author of Solidworks Flow Simulation Thermal. Where this analysis aims to find heat transfer that occurs on each component part of the $3 \mathrm{~d}$ printer. Process flow for analysis and simulation of $3 \mathrm{~d}$ printers can be viewed as process flow image below.

\subsection{Thermal Analysis results on a Model 3D Printer}

On this first model is a $3 \mathrm{~d}$ printer prusa used as research material for the thermal analysis results knows it brings on a component and a component nozzle electrik, after the material already exists then the next is the grant parameters to perform analysis of the flow temperature of the fluid, after completion of the analysis thus obtained analysis results can be seen in the picture below.

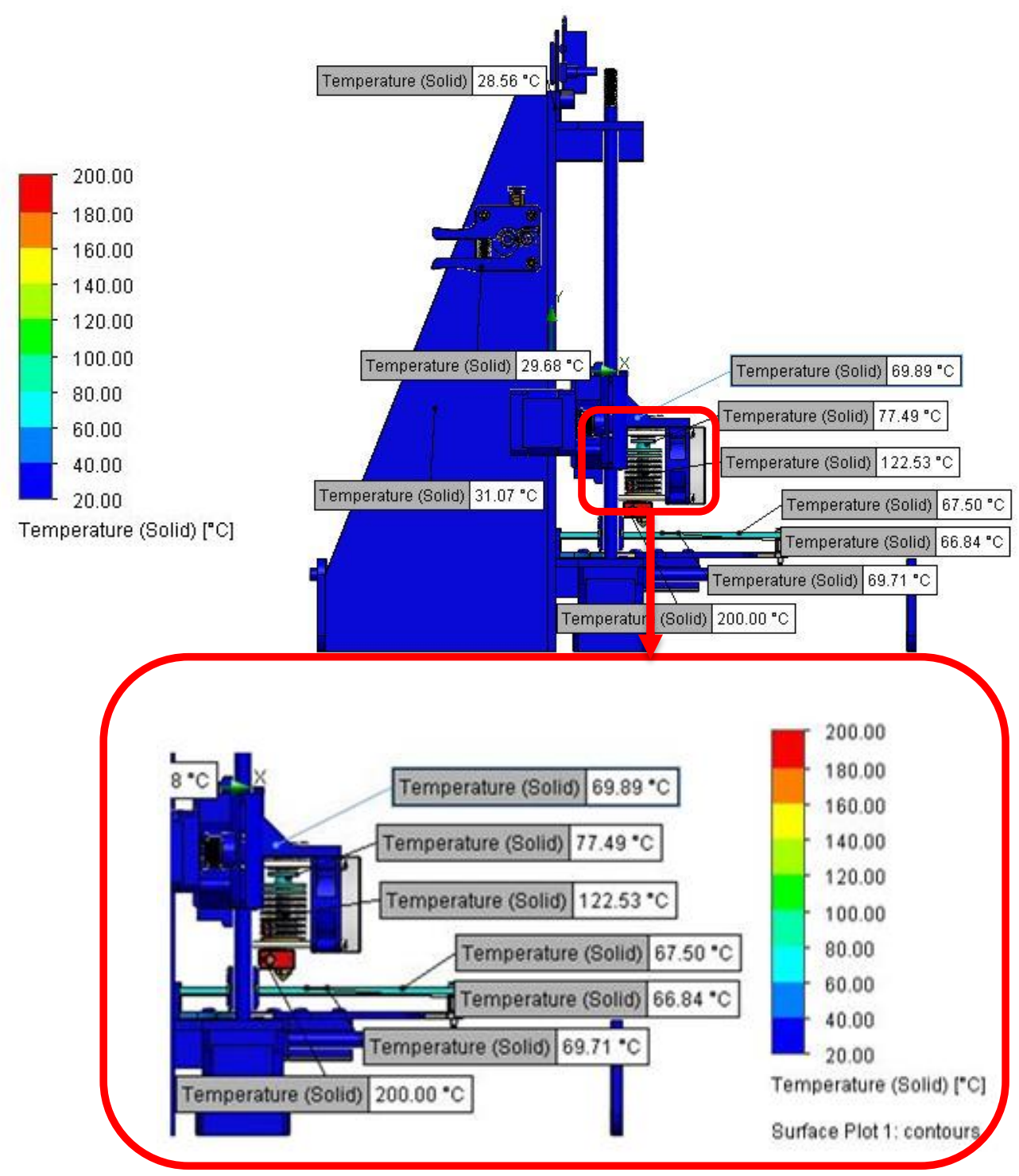

Figure 6 Heat transfer analysis results using the Software Solidworks 3D Printer Thermal Study Prusa I3

Based on the picture above the highest temperature distribution contours look there is the nozzle that is of $200^{\circ} \mathrm{C}$. Where that part is a part to melt the solid becomes liquid filament. Thermal loads received the distinction because of component temperature, then to prevent such things happening in the nozzle installed fan with a size of $5 \mathrm{~mm}$ and there is also a heat sink on the 
part of the nozzle so that the temperature can be reduced When the propagate to other components.

\subsection{Thermal Analysis results on a Model 3D Printer Full Frame Almunium}

This second model is a 3D Printer frame aluminium used as research material for knowing the thermal analysis results obtained on the components of the electrical components and nozzle, analysis results can be seen pada gambar 10 .

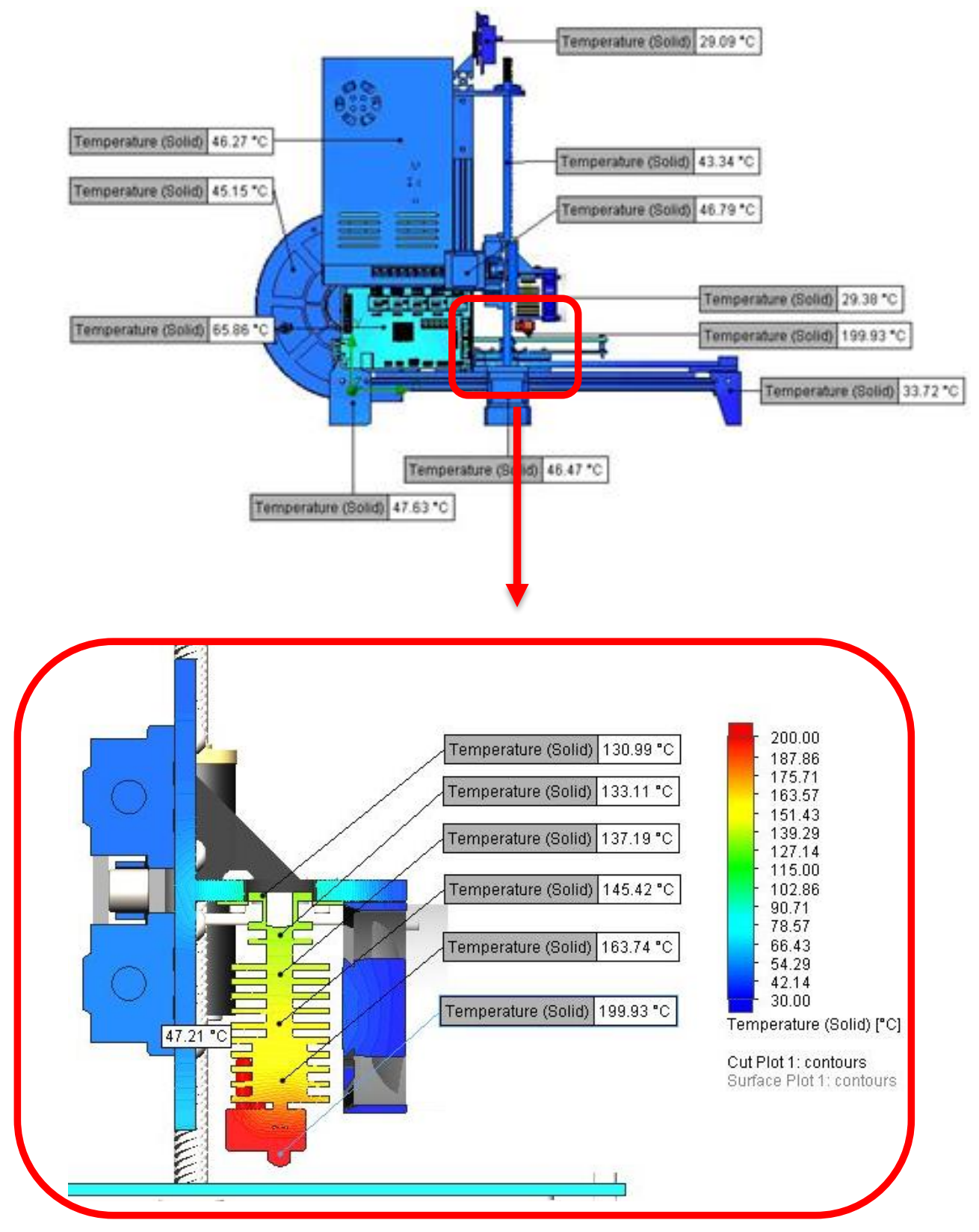

Figure 7 Analysis of heat transfer using Software Solidworks 3D Printer Thermal Study Frame Almunium

Based on the picture above the highest temperature distribution contours look there is the nozzle that is of $199.93^{\circ} \mathrm{C}$. Where that part is a part to melt the solid becomes liquid filament. 


\subsection{Thermal Analysis results on a Model 3D Printer Full Frame Aluminum \& Acrylic Body}

The third model is a 3D Printer Full frame aluminum and acrylic body used as research material for the thermal analysis results knows it brings on the components of the electrical components and the nozzle. The results of this analysis comprise flow trajections and thermal.
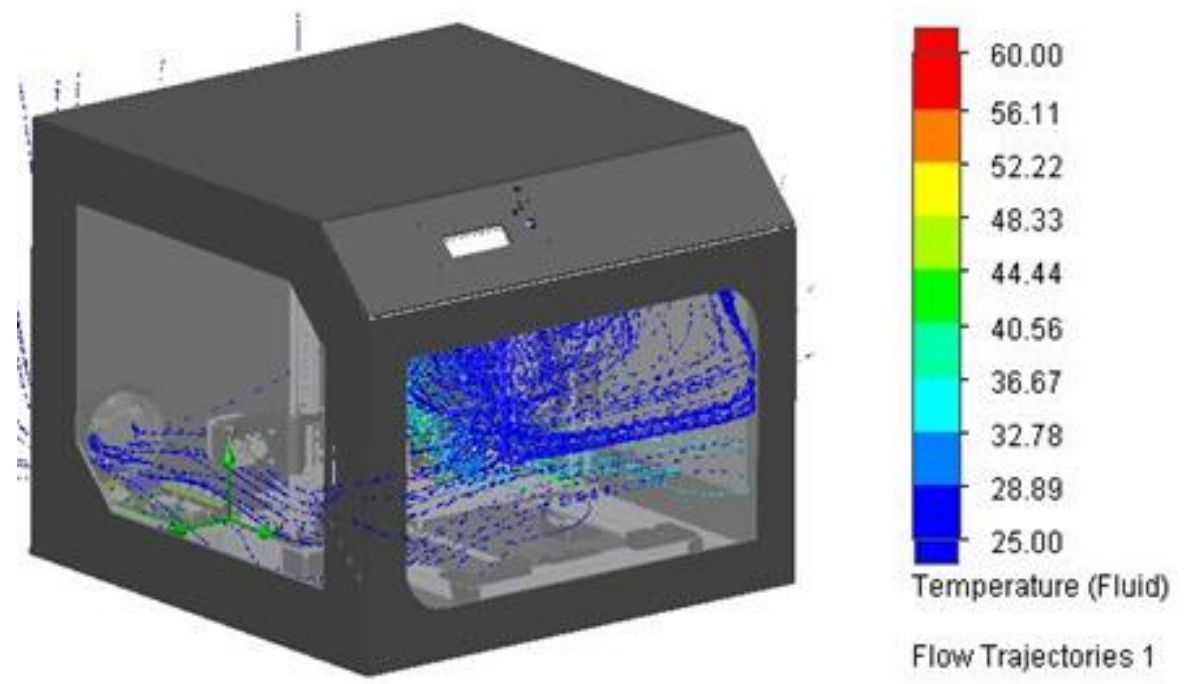

Flow Trajectories 1

Figure 8 Thermal Analysis results on a Model 3D Printer Full Frame Aluminum and Acrylic Body

In Figure 8 is the result of the analysis flow trajectories, where the results of its analysis in the form of simulations of fluid flow that occurs on a $3 \mathrm{~d}$ printer full frame aluminum and acrylic body while Figure 9 is a point Probe.

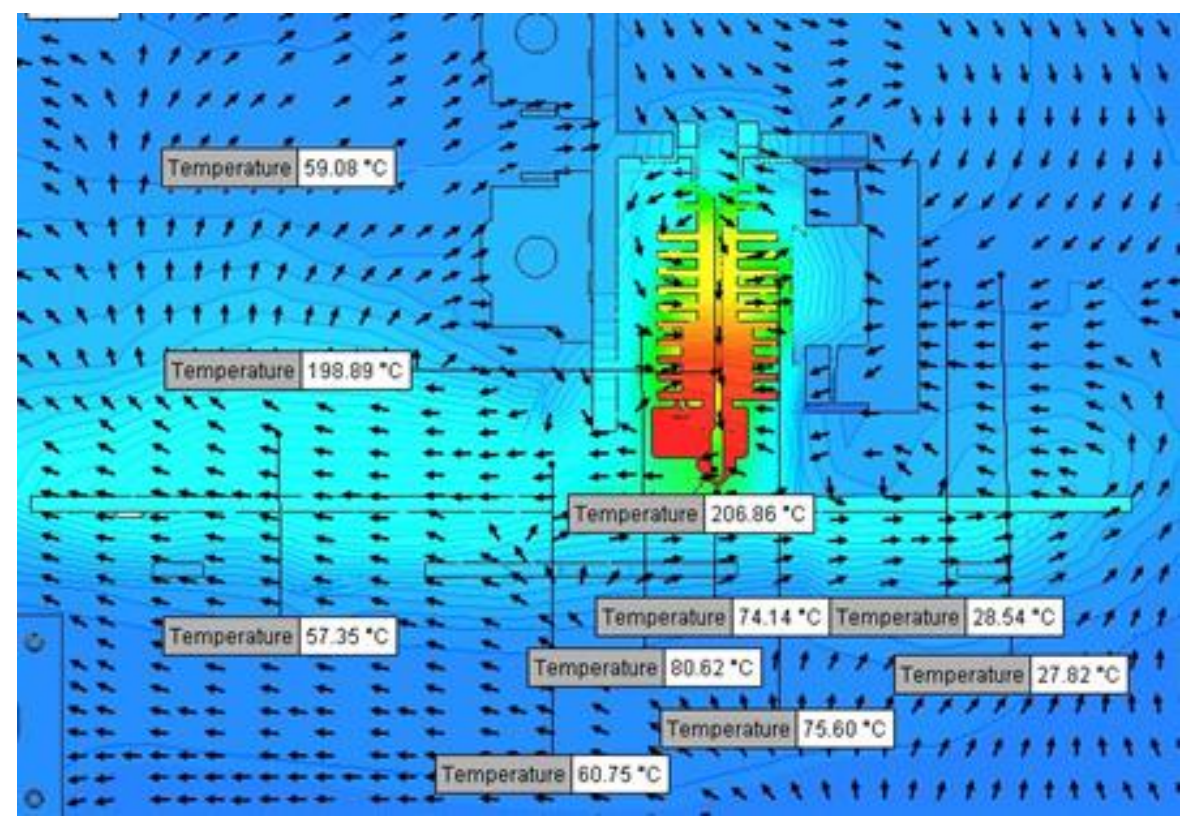

Figure 9 The results Flow Trajectories and point the Probe the inside of the Printer

After knowing the flow trajectories then further discussion regarding thermal analysis that occurs at the printer. Based on the picture below the highest temperature distribution contours look there is the nozzle that is of $207.20^{\circ} \mathrm{C}$. 


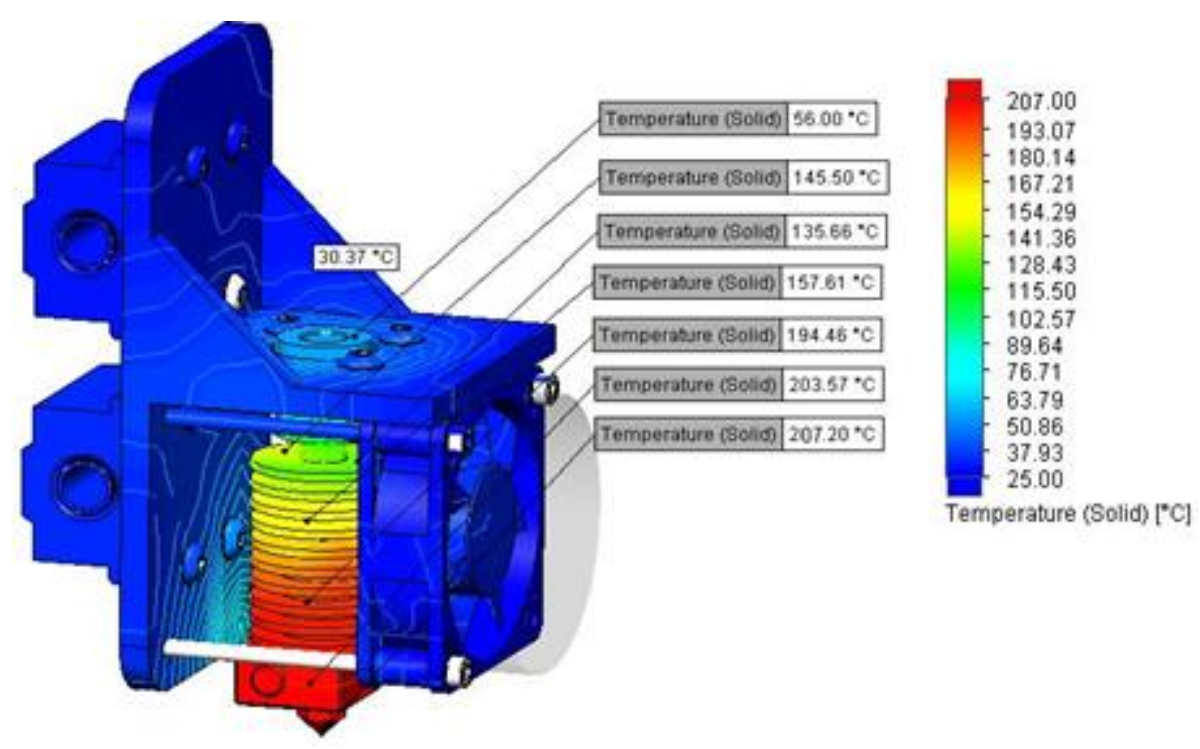

Figure 10 The results Flow Trajectories and point the Probe the inside of the Printer

\subsection{Thrust Analysis of Filament}

Analysis of thrust filament to find the magnitude of the force required for the driving roller so that the filament can flow (due to the urge) to the heater. To find the flow that occurs in the nozzle, so the equation becomes as follows.

$$
\mathrm{Q}_{2}=\mathrm{v}_{2} \times \mathrm{A}_{2}
$$

$\mathrm{Q}_{2}$ indicates the flow at the nozzle. The speed of the flow in the nozzle (v_2) obtained from the initial data, the speed of discharge at nozzle required as great as the speed of the movement of the axes $\mathrm{X}, \mathrm{Y}$, and $\mathrm{Z}$ on a machine that is of $25 \mathrm{~mm} / \mathrm{s}$. nozzle Diameter $0.4 \mathrm{~mm}$.

$$
A=\frac{1}{4} \times \pi \times 0.4^{2}=0.126 \mathrm{~mm}^{2}
$$

To search for great flow on heater

$$
\begin{gathered}
\mathrm{Q}_{1}=\mathrm{Q}_{2:} \\
\mathrm{Q}_{1}=\mathrm{v}_{2} \times \mathrm{A}_{2} \mathrm{Q}_{1} \\
=25 \mathrm{~mm} / \mathrm{s} \times 0.126 \mathrm{~mm}^{2}=3.14 \mathrm{~mm}^{3} / \mathrm{s}
\end{gathered}
$$

Search for the required pressure on the heater.

$$
\begin{gathered}
\mathrm{P}_{1}=\frac{128 \times \mathrm{h} \times \mathrm{Q}_{1}}{\pi} \times\left[\frac{\mathrm{L}_{\mathrm{T}}}{\mathrm{d}_{\mathrm{T}^{4}}} \times \frac{\mathrm{L}_{\mathrm{L}}}{\mathrm{d}_{\mathrm{L}^{4}}}\right] \\
\mathrm{P}_{1}=\frac{128 \times 1.67 \times 10^{-4} \times 3.25}{\pi} \times\left[\frac{0.5}{0.4^{4}} \times \frac{63.7}{1.75^{4}}\right]=2.802 \mathrm{~N} / \mathrm{mm}^{2}
\end{gathered}
$$

Thrust filament.

$$
\mathrm{F}_{1}=\mathrm{P}_{1} \times \mathrm{A}_{1}
$$

The cross-sectional area at the nozzle the thrust required filament

$$
A_{1}=\frac{1}{4} x \pi \times 1.75^{2}=2.419 \mathrm{~mm}^{2}
$$




\subsection{The results of the 3D Printers Type Heater}

After getting the temperature on the position of the heater of $200^{\circ} \mathrm{C}$ up to $2070 \mathrm{C}$ on the results of the analysis, the next is looking for type heater is used, by making use of the data contained in the catalogue of the used heater. From catalog watt low fire rod cartridge/insertion of data obtained for heater type E2A57. To determine the temperature of the heater so that the appropriate temperature is reached. By setting Fit in hole (clearance) between the maximum hole (Inner diameter) reduced the minimum diameter of the heater (Outer Diameter) with a tolerance of $\pm 0.05 \mathrm{~mm}$, where the clearance is obtained with the help of graphs of Maximum Allowable Watt Density Heating Metals Heat Density \& Clearance. Through interpolation retrieved hole fit needed to get the temperature of the heater $200^{\circ} \mathrm{C}$ is 0.299 inch or $0.0118 \mathrm{~mm}$.

\subsection{Analysis of The Speed of Movement of The Filament}

Analysis of the speed of movement of the filament is needed to determine the speed of the shift of the filament (due to the driving style of roller) as well as the speed of rotation of the motor that is required in order for the resulting speed of the discharge that comes out of the nozzle. The great streams that are needed on a space heater that is Q1 $=3.14 \mathrm{~mm} 3 / \mathrm{s}$, then the speed of the shift of the filament on the space heater $(\mathrm{v} 1)=0.12 \mathrm{~m} / \mathrm{s}$. After known speed shift filament, then assuming isn't the case slip on contact between the filament tooth profile with plastic on a skewer, with a diameter of roller roller design results of $1,725 \mathrm{~mm}$, the speed of rotation of the roller (nr) can be searched by.

$$
\mathrm{N}_{\mathrm{r}}=\frac{v_{1}}{k e l}=\frac{v 1}{\pi \times d}=\frac{v_{1}}{\pi \times 1.725}=0.022
$$

then $\mathrm{nr}=0.022 \mathrm{rps}=1,358 \mathrm{rpm}$. Before it is forwarded to the roller, rounds of motor are reduced in advance using the wheel straight teeth. From the resulting design, the number of teeth on the gears small $(\mathrm{z} 1)=18$ and the number of teeth on the gears $(\mathrm{z} 2)=72$. Then the ratio of the round (i).

$$
i=\frac{72}{18}=4
$$

the speed of rotation of the motor $(\mathrm{nm})$ is required. $\mathrm{NM}=\mathrm{nr} \times \mathrm{I}=\mathrm{x} 4=1.3585,433 \mathrm{rpm}$. From the literature it is known that the speed limit NEMA17 stepper motor to spin allowed is 2,127 - so that the speed of the motor rpm 127,323 stepper needed still in the allowable limits. To produce filament discharge speed of $25 \mathrm{~mm} / \mathrm{s}$ then it needs to be arranged a round of 5,433 motor rpm. Also calculated motor power required to produce the corresponding filament movement.

$$
2 \mathrm{Fp} \leq\left(\pi \times 1.52^{\frac{2}{3}} x \frac{16^{\frac{1}{3}}}{3543.9^{\frac{1}{3}}} \times 0.65 \times 65.5\right)^{3 / 2}=2 \mathrm{Fp} \leq 157.98 \mathrm{~N}
$$

Then the great style of press due to the spring must meet both of these restrictions so that selected $2 \mathrm{Fp}=40 \mathrm{~N}, \mathrm{Fp}=20 \mathrm{n}$. and selected spring 20N. Due to the spring produce friction on the filament. Friction happens.

$$
\mathrm{Fg}=2 \mathrm{Fp} \times \mu \mathrm{k}=40 \times 0.1=4 \mathrm{~N}
$$

Thrust filament $(\mathrm{F} 1)$ is the reduction of style roller $(\mathrm{Fr})$ and friction $(\mathrm{Fg})$.

$$
\mathrm{Fr}=\mathrm{F}_{1}+\mathrm{Fg}=6.778+4=10.778 \mathrm{~N}
$$

Power of the motor can be searched by using the power equation.

$$
\operatorname{Pr}=\operatorname{Fr} \times v_{1}=10.778 \mathrm{~N} \times 1.29 \mathrm{~mm}=\frac{10.778 \mathrm{~N} \times 1.29 \mathrm{~m} / \mathrm{s}}{1000}=0.0139 \mathrm{Watt}
$$


Efficiency of $85 \%$ of the gear motor power then becomes

$$
P m=\frac{P_{r}}{\tau}=\frac{0.0139}{0.85}=0.016 \mathrm{Watt}
$$

\section{CONCLUSION}

1. Based on the results of the analysis of the third $3 \mathrm{~d}$ printer models on the components of the heater and nozzle can be the conclusion.

2. 3D printers are designed using FDM, where this method is utilizing the material extruded from a nozzle that is then driven by the motor. The material is a thermoplastic shaped yarn (coil) that is heated above the melting point by the heater is then extruded through the vent extruder nozzle. Maintain the temperature of the heater and deformation material from a solid into a semi-solid (liquid) for easy extruded.

3. The results of the analysis of the subject of the flow temperature of the fluid and heat transfer by convection on three models, namely:

- the results of the analysis on the position of the $3 \mathrm{~d}$ printer models prusa heater of $200^{\circ}$ C.

- results of the analysis on the position of the $3 \mathrm{~d}$ printer model heater full frame aluminum of $199.93^{\circ} \mathrm{C}$.

- results of the analysis on the position of the $3 \mathrm{~d}$ printer model heater full aluminum frame and the acrylic body of $207^{\circ} \mathrm{C}$.

4. Based on the results obtained by E2A57 type heater, based on the catalogue of wattlow firerod cartridge/insertion heater.

5. Analysis of thrust filament aims to find the magnitude of the force required for the driving roller so that the filament can flow (due to the urge) to the heater, the results obtained, namely $6,778 \mathrm{~N}$.

6. The analysis of the speed of movement of the filament is needed to determine the speed of the shift of the filament (due to the driving style of roller) as well as the speed of rotation of the motor that is required in order for the resulting speed of the discharge that comes out of the nozzle fit that is $25 \mathrm{~mm} / \mathrm{s}$, thus obtained the appropriate stepper motor IE NEMA17.

\section{REFERENCES}

[1] Autonomie. Dassault Systèmes SolidWorks Corporation, a Dassault Systèmes S.A. company, 175 Wyman Street, Waltham, Mass. 02451 USA, 2016.

[2] Chua, C.K., Leong, K.F., and Lin, C.S. Rapid Prototyping Principles and Applications (second edition), World Scientific Publish Co, Pte. Ltd.5 Toh Tuck Link, Singapore, 2003.

[3] Custompartnet. Additive Fabrication [Online], 2017, http://www.custompartnet.com/.

[4] Jim, Jose, dan Rajakannu Amuthakkannan. Design, Development and Analysis of FDM based Portable Rapid Prototyping Machine." International Journal of Latest Trends in Engineering and Technology (IJLTET), 2014.

[5] Kamrani, Ali K dan Nasr, Emad A. "Rapid Prototyping: Theory and practice", Industrial Engineering Department of Houston, USA, 2006.

[6] Kelly, James Floyd, dan Patrick Hood Daniel. Printing in Plastic - Build Your Own 3D Printer. New York: Apress, 2011.

[7] Rafiq, Noorani. Rapid Prototyping Principles and Applications, Jhon Milley\&sous. Ine, 2006. 